\title{
Selecting Serious Games for the Computer Science Class
}

\section{JW Prinsloo}

\section{DB Jordaan}

\author{
North-West University, Faculty of Economic Sciences and Information Technology
} PO Box 1174, Vanderbijpark, 1900, Republic of South Africa

Doi:10.5901/mjss.2014.v5n21p391

\author{
Email: Johan.Prinsloo@nwu.ac.za
}

\section{Abstract}

The aim of this paper was to investigate models to select serious games for use in the computer science class. The lack of a useful framework to select serious games that meet the teaching and learning objectives presented a significant obstacle when serious games where introduced into tertiary education. This paper briefly discusses three frameworks, the RETAIN model, the four-dimensional framework, and the magic bullet model. Lecturers evaluated serious games using the guidelines suggested by each of these models and their perceptions of the models were captured using a short questionnaire. Using descriptive analysis to analyse the data, the results are that lecturers prefer the four-dimensional framework when considering and selecting serious games as a teaching tool in the computer science class.

Keywords: serious games; computer science

\section{Introduction}

Computer or digital games with an educational intention to teach specific predefined skills and knowledge are called serious games (Ulicsak \& Wright, 2010). A successful serious game is much more than just an engaging atmosphere and the incorporation of academic content (Gunter, Kenny \& Vick, 2008). Every stage of the design and production requires lots of thought and planning to make sure that media and content match, content is integrated and intertwined closely with game play, and learning is supported with well-planned feedback and hints (Gunter et al., 2008).

Learning environments can be transformed to be more effective and powerful using serious games (Wrzesien \& Alcañiz Raya, 2010). Serious games are incorporated more and more into the learning and training programmes of many learning environments, for example classrooms, healthcare training, corporate and military training (Guillén-Nieto \& Aleson-Carbonell, 2012).

Introducing serious games and simulations into tertiary education presented a significant obstacle because of the lack of a useful framework to select an appropriate serious game to meet teaching and learning goals (De Freitas, 2006). The first important challenge in selecting serious games for teaching and learning purposes is to identify if a game exists that addresses the identified teaching and learning goals (Bogost, 2010). The next challenge is finding relevant games in that area, identifying whether one of the games will enhance teaching, and if not, identifying what will be needed for a game to be useful.

Researchers have tried to identify the issues involved in selecting, developing and evaluating serious games used for education. One example is the Games for Learning Institute (Hoffman, 2010). They created a checklist that offers 17 different areas on a five-point scale, whereby designers can evaluate educational games against three criteria, namely technical implementation, educational appropriateness, and overall integration with goals. Other models that are used to select serious games for the teaching and learning environment are the RETAIN model, the four-dimensional framework and the magic bullet model.

\section{Model to Select Serious Games}

\subsection{The RETAIN model}

Gunter et al. (2008, p. 511) summarise the relevance, embedding, transfer, adaption, immersion and naturalisation (RETAIN) model as follows:

The RETAIN design and evaluation model for educational games was developed to aide in the evaluation of how 
well academic content is endogenously immersed and embedded within the game's fantasy and story content, promotes transfer of knowledge, and encourages repetitive usage to that content becomes available for use in an automatic way.

Ulicsak and Wright (2010) summarise the purpose of the RETAIN model as a model to support game development and to assess how well educational games contain and incorporate academic content. Once the learning goals have been set, the game designer or lecturer has to consider the six areas of the RETAIN model, briefly summarised by Ulicsak and Wright (2010) as follows:

- Relevance. Materials presented must be relevant to learners' needs and learning style. In addition, instructional units should be relevant to each other, and must link together and become more advanced as the learner's skill increases.

- Embedding. Evaluating how well academic content is embedded in the game's story or fantasy.

- Transfer. Access how knowledge is transferred from previous tasks and scenarios to other areas.

- Adaption. The adaptability created as a consequence of transfer. Adaption refers to learners being forced to change or create new knowledge to deal with something that does not fit existing ideas and understanding.

- Immersion. Judging the learners intellectual investment in the context of the game.

- Naturalisation. To access how well learners develop automated or spontaneous use of information.

The evaluation guidelines in the RETAIN model are represented in a table format (Table 1). The suggested elements are in the table and a bottom-up hierarchy is assumed in which the evaluation of one element builds upon the previous element. Each of these elements can be divided into four levels: 0, 1, 2 and 3, where Level 0 indicates the game design does not meet that aspect, while Level 3 means there is a strong correlation between the game and that specific aspect. For example, naturalisation would be classified as Level 0 if there is little opportunity to use the information already presented again; Level 1 if it does require the player to use the information and encourage him/her to process it more quickly; Level 2 if the player has to make judgements about ideas and materials; and Level 3 if the player can incorporate information from multiple sources and use it spontaneously and habitually. A value system associated with the set of instructions and the evaluation criteria to determine how the proposed designs can be assessed is outlined in Table 1.

Table 1. Summary of RETAIN rubric (Gunter et al., 2008:524)

\section{CATEGORY 1: Relevance}

Explanation: Learning material and its presentation should be relevant to the learner and instructional units must be relevant to each other

\begin{tabular}{|c|c|}
\hline Level 0 & Little stimulus for learning \\
\hline Level 1 & Limited educational focus, some irrelevant content \\
\hline Level 2 & Learning objectives are defined, interest is created \\
\hline Level 3 & Game is relevant to learners, and challenges or adequate for learning \\
\hline & CATEGORY 2: Embedding \\
\hline \multicolumn{2}{|c|}{ Explanation: How close the academic content is coupled with the fantasy/story } \\
\hline Level 0 & Learning content disrupts play \\
\hline Level 1 & Learning is exogenous to fantasy context (learning is "outside" the fantasy context) \\
\hline Level 2 & Includes intellectual challenge and problems \\
\hline Level 3 & Content is endogenous to fantasy and fully involves learner \\
\hline \multicolumn{2}{|r|}{ CATEGORY 3: Transfer } \\
\hline \multicolumn{2}{|c|}{ Explanation: The transfer of knowledge from one level to another } \\
\hline Level 0 & No levels of challenge mapped to objectives \\
\hline Level 1 & Levels of challenge are too similar, some useful content \\
\hline Level 2 & $\begin{array}{l}\text { Easy progress through levels through active problem solving. Higher level knowledge should be } \\
\text { transferable }\end{array}$ \\
\hline Level 3 & Authentic real life situations and after action reviews \\
\hline \multicolumn{2}{|r|}{ CATEGORY 4: Adaption } \\
\hline \multicolumn{2}{|r|}{$\begin{array}{l}\text { Explanation: Refers to learners being forced to change or create new knowledge to deal with something that does not fit existing } \\
\text { ideas and understanding }\end{array}$} \\
\hline Level 0 & Fails to engage in interactive, unstructured information \\
\hline Level 1 & Builds upon existing cognitive structures, engages in cognitive conflict \\
\hline Level 2 & $\begin{array}{l}\text { Learners are encouraged to go beyond given information. Old schemas are identified and adapted } \\
\text { to new situations }\end{array}$ \\
\hline Level 3 & Learning becomes an active process that integrates prior knowledge \\
\hline
\end{tabular}


CATEGORY 5: Immersion

\begin{tabular}{|}
\hline \multicolumn{2}{|c|}{ Explanation: The learners intellectual investment in the context of the game } \\
\hline Level 0 & No formative feedback, little active participation \\
\hline Level 1 & Elements of play are not in sync with learning objectives, players do not feel fully interactive \\
\hline Level 2 & Learners are involved cognitively, physically and emotionally \\
\hline Level 3 & Favours belief creation and includes opportunities for reciprocal action \\
\hline \multicolumn{2}{|c|}{ CATEGORY 6: Naturalisation } \\
\hline Explanation: How well learners develop automated or spontaneous use of information \\
\hline Level 0 & Little opportunity for mastery of facts and skills \\
\hline Level 1 & Replay is encouraged to improve speed of processing \\
\hline Level 2 & Encourages synthesis of elements and judgments \\
\hline Level 3 & Learners become efficient content users and spontaneously use acquired knowledge \\
\hline
\end{tabular}

A twofold weighting system is used in the RETAIN model. The first weighting occurs within the levels next to the aspects. Level 0 implies that the conceptual construct for that element is missing; at Level 1 that conceptual construct is there but very minimal and increases as one move to Levels 2 and 3.

For the second weighting, the aspects are ordered from the least to the most important. These aspects are relevance, immersion, embedding, adaption, transfer and naturalisation. In this case, points are awarded as more proof of that element's construct is present, according to the specifications provided in the specific cell of Table 1 . The weighting chart is shown in Table 2.

Table 2. RETAIN weighting chart (Gunter et al., 2008)

\begin{tabular}{|l|c|c|c|c|c|}
\hline & Order of importance & Level 0 & Level 1 & Level 2 & Level 3 \\
\hline Relevance & 1 & 0 & 1 & 2 & 3 \\
\hline Embedding & 3 & 0 & 3 & 6 & 9 \\
\hline Transfer & 5 & 0 & 5 & 10 & 15 \\
\hline Adaptation & 4 & 0 & 4 & 8 & 12 \\
\hline Immersion & 2 & 0 & 2 & 4 & 6 \\
\hline Naturalization & 6 & 0 & 6 & 12 & 18 \\
\hline
\end{tabular}

To obtain the weighting of a specific element at a specific level, multiply the level number with that element's order of importance number. For example if a game fulfils Level 0 of adaptation, it is worth zero points $\left(0^{\star} 4\right)$, Level 1 , four points $\left(1^{\star} 4\right)$, Level 2, eight points $\left(2^{\star} 4\right)$, and Level 3, 12 points $\left(3^{\star} 4\right)$. Since relevance is seen as a less essential aspect of serious game design, this would mean if a game fulfilled Level 1 requirements it would be worth one point (1*1), Level 2, two points (2*1), and so on.

Each serious game or game design could be assessed using this framework (Ulicsak \& Wright, 2010). If a game fulfils Level 3 at all aspects, it would be awarded a maximum of 63 points. Based on these scores, the most appropriate game would be constructed or selected for use.

\subsection{The four-dimensional framework}

The need by lecturers to understand more about how games are used and selected for educational purposes triggered the design of the four-dimensional framework (De Freitas \& Jarvis, 2008). The four-dimensional framework, proposed by De Freitas and Oliver (2006), is a structured analysis designed in the first place to assist the processes to select the correct content and games, and secondly, to find the best way to apply it within the learning context. The fourdimensional framework consists of a set of four interrelated elements, namely context, learner specification, mode of representation and pedagogic considerations. Ulicsak and Wright (2010) summarise these four elements of the fourdimensional framework as follows.

- Context. Context covers where the learning occurs, ranges from the macro level, that is historical, political and economic factors (for example, are you playing because it is a school directive?), to the micro level, that is the lecturer's background and experience, cost of game licenses, etcetera.

- Learner specification. The individual learner or the group requires the lecturer to consider the learners' preferred learning style, previous knowledge, and what methods would best support them given their differing needs. 
- Mode of representation (how high the levels of fidelity need to be, how interactive the game is, and how immersive the game might be). The representation also covers diegesis (diegesis is a term used frequently in film studies and means the world within the narrative film or the story world), the separation of the immersion aspect with the reflection around the process of playing the game. Most importantly, it highlights the potential of briefing and debriefing to reinforce the learning outcomes.

- Pedagogic principles (for example, associative, cognitive, and situative). Require the lecturer to reflect on the learning models, which enables them to produce appropriate lesson plans.

These elements cannot be considered individually as they are interrelated. An iterative process is followed by addressing a set of checklist questions for each element of the framework. These questions can be very broad, for example What is the context? to very specific, for example What level of fidelity needs to be used to support learning activities and outcomes? Table 3 presents the checklist of questions, as suggested by De Freitas and Oliver (2006). The structure of the questions means they are suited for educational software designers or for those in educational advisory roles. If the questions need to be used directly by a lecturer, they may need refining.

Table 3. Checklist for evaluating the use of educational games and simulations (De Freitas \& Oliver, 2006)

\begin{tabular}{|c|c|c|c|}
\hline Content & Learner specification & Pedagogic consideration & Mode of representation \\
\hline $\begin{array}{l}\text { What is the context for } \\
\text { learning? (e.g., school, } \\
\text { university, home, a } \\
\text { combination of several) } \\
\text { Does the context affect } \\
\text { learning? (e.g., level of } \\
\text { resources, accessibility, } \\
\text { technical support) } \\
\text { How can links be made } \\
\text { between context and } \\
\text { practice? }\end{array}$ & $\begin{array}{l}\text { Who is the Learner? } \\
\text { What is their background and } \\
\text { learning history? } \\
\text { What are the learning } \\
\text { styles/preferences? } \\
\text { Who is the learner group? } \\
\text { How can the learner or learner } \\
\text { group be best supported? } \\
\text { In what ways are the groups } \\
\text { working together (e.g., singly, } \\
\text { partially in groups) and what } \\
\text { collaborative approaches could } \\
\text { support this? }\end{array}$ & $\begin{array}{l}\text { Which pedagogic models and } \\
\text { approaches are being used? } \\
\text { Which pedagogic models and } \\
\text { approaches might be most } \\
\text { affective? } \\
\text { What are the curricula objectives? } \\
\text { (list them) } \\
\text { What are the learning outcomes? } \\
\text { What are the learning activities? } \\
\text { How can the learning activities and } \\
\text { outcomes be achieved through } \\
\text { specially developed software (e.g., } \\
\text { embedding into lesson plans)? } \\
\text { How can briefing/debriefing be } \\
\text { used to reinforce learning } \\
\text { outcomes? }\end{array}$ & $\begin{array}{l}\text { Which software tools or } \\
\text { content would best support } \\
\text { the learning activities? } \\
\text { What level of fidelity needs to } \\
\text { be used to support learning } \\
\text { activities and outcomes? } \\
\text { What level of immersion is } \\
\text { needed to support learning } \\
\text { outcomes? } \\
\text { What level of realism is } \\
\text { needed to achieve learning } \\
\text { objectives? } \\
\text { How can links be made } \\
\text { between the world of the } \\
\text { game/simulation and } \\
\text { reflection upon learning? }\end{array}$ \\
\hline
\end{tabular}

\subsection{The magic bullet model}

Becker (2007) developed the instructional ethology methodology intended to analyse videogames for learning in a formal manner. From this, a by-product called the magic bullet model emerged. During gameplay, some learning might occur that was never planned by the designers, and not all learning during gameplay is necessary to win the game. Becker (2012) analysed gameplay logs and realised that all learning that take place can be classified into four broad sets, where learning belongs to at least one of the four sets. The four sets are described briefly as follows:

- Things that can be learnt while playing a game. In this category, learning is not essential to achieve the game's goal. The game design includes specific learning elements as deliberate goals of the game. These learning elements can include learning from all domains (cognitive, psychomotor and affective) and all categories (remembering, understanding, applying, analysing, evaluating and creating (Anderson, Krathwohl \& Bloom, 2001).

- Things that must be learnt in order to complete the game. This category consists of only those items that are crucial for winning, or to complete the game. Sometimes it may be necessary to qualify these items with an ifthen statement, as many games allow for more than one way to win or to get to the end of the game.

- Things learned as a result of playing the game, but are not part of the game (collateral learning). This category includes other things that can be learned or an emergent behaviour that is not part of the game and does not have an impact upon the player's success in the game.

- Things learned outside the game that are helpful when the game is played again (external learning). External learning takes place outside the game for instance in fan sites or social events, or where game guides are provided. 


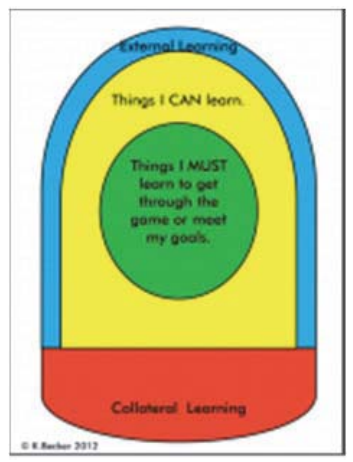

Figure 1. The Magic Bullet (Becker, 2012)

The shape of the image illustrated in Figure 1 inspired the name of this model. Figure 1 depicts what Becker (2012) calls a good-balanced game. What I must learn is completely inside what I can learn, and it is possible that external and collateral learning can also take place. This means that the game provides much more to learn than just what is necessary to meet the goals or complete the game.

\section{Rationale for the Study}

The potential benefits of serious games as significant teaching tools in education have been explored by many researchers (Gee, 2008; Smith, 2007; Shaffer, 2005; Ulicsak \& Wright, 2010), but the use of games in education is still limited (Westera, Nadolski, Hummel \& Wopereis, 2008). Harteveld and Bidarra (2007) distinguish between the postindustrial way of learning and thinking as the traditional paradigm and the interactive, entertaining and authentic way of learning and thinking as the gaming paradigm. How this gaming paradigm should be implemented to create an effective learning experience is unclear (Shaffer, Squire, Halverson \& Gee, 2005). "Many organisations, including schools and universities, considering the adoption of digital game-based learning don't know where to begin. The sheer variety and depth of the digital game experience makes it difficult to decide on a strategy and approach" (Kadle, 2009:5).

The purpose of this study was to identify a suitable model for selecting serious games for the computer science class. The results may be useful in identifying a model to evaluate and select serious games for use in the computer science class. The results may also indicate whether research should be conducted in developing new models for evaluation of serious games, especially for use in the computer science class.

\section{Purpose of the Study}

The purpose of this study was to identify a suitable model to select serious games for the computer science class.

\section{Research Methodology}

A quantitative research approach was followed, and a questionnaire was used to collect data for the study. In addition, an appropriate literature review on models to select serious games as educational aids was conducted.

\subsection{Sample and procedure}

The sample for the study consists of fifteen computer science lecturers from one university campus in the Gauteng province of South Africa. All the lecturers teach computer science modules in the School of Information Technology at the Vaal Triangle Campus of the North-West University in South Africa. The participants have between two and 30 years teaching experience in computer science.

\subsection{Research instrument}

From the literature review, a questionnaire was developed to investigate lecturers' preferences towards different models 
to select serious games for use in the computer science class. This approach was chosen because questionnaires seemed to be the best option to evaluate participants' perceptions and preferences after they evaluated different models for appropriateness of use in the computer science class. The questionnaire used to collect data during the interviews comprised eight items examining lecturers' perceptions on the appropriateness of three different models used to select serious games for use in the computer science class. Items included aspects of the usefulness of the model, and how well the models address the objectives of the learning module. The perception items were scored on a four-point Likerttype scale with 1=strongly agree and 4=strongly disagree.

\subsection{Ethical considerations}

The principal researcher administrated the evaluation process and the questionnaire to the participants personally. Participants were informed of the purpose of the study, that participation was voluntary, and that the data collected from the study would be reported in a summative format. They were assured of anonymity and confidentiality.

\section{Results}

Six computer science lecturers agreed to take part in this study and data were collected from all of them.

\section{Discussion}

The analysis of the data revealed the following.

It was easy for me to understand the model. Participants were presented with a brief description of each model, which included the main philosophy of the model, the aims of the model, and the layout of the model. With a score of 83 percent for the magic bullet model, 83 percent for the RETAIN model, and 100 percent for the four dimensional model, the participants indicated that all three models were fairly well understood.

The model is clear and easy to use. Participants found the RETAIN and the four dimensional models easier to use than the magic bullet model, with overall scores of 83 percent for the RETAIN model and 100 percent for the four dimensional model. The magic bullet model scored only 50 percent.

I found the model to be useful. This study aims to identify a model that can be used to select a suitable serious game (or games) to enhance the learning experience in the computer science class. To select the serious game (or games) the selection tool (or model) must be helpful in assisting the lecturer in the selection process. The participants scored the helpfulness of the magic bullet model lower (17\%) against the helpfulness of the RETAIN model (83\%) and the four dimensional model (83\%).

I would use this model again if I need to evaluate a game for class use. One way to determine user satisfaction in terms of appropriateness and usefulness of the specific model is to determine whether the user will use the model again in future to evaluate serious games for use in class. In response to this question participants voted in favour of the RETAIN model (67\%) and the four dimensional model (67\%). The magic bullet model was rated lower with a score of 17 percent.

I will suggest the use of this model to colleagues when they need to evaluate games for class use. This question relates to the previous question in the sense that it also evaluates the usefulness of the specific model with the added expectation that the model will be recommended to colleagues when they want to select serious games to enhance the learning experience of learners. In this case, the four dimensional model was rated the highest score of 83 percent while the RETAIN model scored 67 percent and the magic bullet 17 percent.

This model does not address the needs when it comes to evaluating games for class use. The main purpose of any model used to select a serious game for use in class is to address the objectives of the learning module in consideration. With a score of 83 percent for the magic bullet model, the majority of participants agreed that this model did not address the requirements to evaluate games for the computer science class. The RETAIN model, with 33 percent, was a better choice, but the four dimensional model, with a score of 17 percent, was voted the best model to address the evaluation criteria for selecting a serious game for the computer science class.

I found the use of this model to be a waste of time. This question is linked closely to the previous question and addressed the usefulness of the models. If a model is seen to be useless, it will be evaluated as a waste of time to use the model for selecting serious games. With a score of 67 percent, the majority of the participants indicated that the use of the magic bullet model was a waste of time. The RETAIN model (17\%) and the four dimensional model (17\%) were not perceived as a waste of time in evaluating a serious game for the computer science class. 
This model adds any value when evaluating a game. The main purpose of any model used in selecting serious games to assist learners, and to enhance the learning environment, is to add value to the selection and evaluation process of the serious game. When asked whether the model adds value to the selection process, participants agreed that the four-dimensional model (83\%) is far better than the RETAIN model (67\%) and the magic bullet model (50\%).

\section{Limitation and Implications for Further Research}

The sampling method is a limitation of this study. The sample was taken from one university campus in one of the nine provinces in South Africa. Generalisation of the results of this study should be exercised with extreme care.

This study was conducted only for the computer science class, and it could be very interesting to compare these results with the results of a similar study in other disciplines. Extending the study to other disciplines, and to other universities in other provinces in South Africa, and comparing the results, may provide a more comprehensive illustration of the suitability of existing models used to select serious games for use in lectures.

\section{Conclusion}

The purpose of this study was to investigate and identify models to select serious games for use in the computer science class. The study revealed that computer science lecturers, the participants in this study, chose the four dimensional model to select serious games for use in the computer science class. The RETAIN model was the second choice, and the magic bullet the last choice.

\section{References}

Anderson, L. W., Krathwohl, D. R., \& Bloom, B. S. (2001). A taxonomy for learning, teaching, and assessing: a revision of Bloom's taxonomy of educational objectives. New York: Longman.

Becker, K. (2007). Instructional ethology: reverse engineering for serious design of educational games. FuturePlay, November, 15-17.

Becker, K. (2012). A magic bullet for assessing games for learning. Paper presented at the Society for Information Technology \& Teacher Education International Conference 2012, Austin, Texas, USA; March 5-9.

Bogost, I. (2010). Playing political games on the white house and videogames. [Online] Available: www.bogost.com/blog /playing_political_games.shtml. (April 14, 2014).

De Freitas, S., (2006). Learning in immersive worlds: a review of game based learning, JiSC. [Online] Available: www.jisc.ac.uk/ whatwedo/programmes/elearninginnovation/outcomes.aspx

De Freitas, S., \& Oliver, M., (2006). How can exploratory learning with games and simulations within the curriculum be most effectively evaluated? Computers \& Education, 46(3), 249-264.

De Freitas, S., \& Jarvis, S. (2008). Towards a development approach for serious games.

Gee, J. P. 2008. Getting over the slump: innovation strategies to promote children's learning, Joan Ganz Cooney Center.

Guillén-Nieto, V., \& Aleson-Carbonell, M. (2012). Serious games and learning effectiveness: the case of it's a deal! Computers \& Education, 58.

Gunter, G. A., Kenny, R. F., \& Vick, E. H. (2008). Taking educational games seriously: using the RETAIN model to design endogenous fantasy into standalone educational games. Education Tech Research Dev, 56:511-537.

Harteveld, C., \& Bidarra, R. (2007). Learning with games in a professional environment: a case study of a serious game about levee inspection.

Hoffman, D. (2010). Game design patterns rubric presnted at GLS 6.0. [Online] Available: http://g4li.org/research?topic=Rubric

Kadle, A. (2009). Do you need games in your elearning mix? A white paper by Upside Learning Solutions. India: Upside Learning Solutions Pvt. Ltd.

Shaffer, D. W. (2005). Epistemic games. Innovate: Journal of Online Education, 1(6).

Shaffer, D. W., Squire, K. A., Halverson, R., \& Gee, J. P. (2005). Video games and the future of learning. Phi Delta Kappan, 87, 104-111.

Smith, R. (2007). Game impact theory: the five forces that are driving the adoption of game technologies within multiple established industries. Games and Society Yearbook.

Ulicsak, M. \& Wright, M. (2010). Games in education: serious games. A Futurelab literature review. Futurelab. United Kingdom, June. [Online] Available: www.futurelab.org.uk

Westera, W., Nadolski, R. J., Hummel, H. G. K., \& Wopereis, I. G. J. H. (2008). Serious games for higher education: a framework for reducing design complexity. Journal of Computer Assisted Learning, 24, 420-432

Wrzesien, M., \& Alcañiz Raya, M. (2010). Learning in serious virtual worlds: evaluation of learning effectiveness and appeal to students in the E-Junior project. Computers \& Education, 55. 
